\title{
Biparental Mating; A System of Intermating for Creating Genetic Variability in Segregating Generation for Crop Improvement
}

\author{
N.R. Koli ${ }^{*}$, B.K. Patidar ${ }^{2}$, Manoj Kumar ${ }^{3}$ and Sandhya ${ }^{4}$ \\ Agricultural Research Station, Ummedganj Farm KOTA -324001 \\ (Agricultural University, Kota), India \\ *Corresponding author
}

\section{Keywords \\ Biparental mating design, Genetic variability, Additive and dominance component of variance and segregating generation \\ Article Info \\ Accepted: 20 July 2018 Available Online: 10 August 2018}

\section{A B S T R A C T}

Biparental mating is helpful for creating variability and determines the relative importance of genetic components of variance (additive and dominance components of variance) as well as expected response to selection of a trait in formulating and effective breeding programme for its genetic improvement. Both additive and dominance components of variance shows significance for yield and yield contributing characters. In general, biparental population (BIP) had better mean performance than the selfing series for all the characters. The lower and upper limit of range generally increases with high genetic variance is maintained in the BIP population for most of the characters. BIP also exhibited improved estimates of heritability and genetic advances. Thus, the utility of the biparental mating in early segregating generation is emphasized in crop improvement programme.

\section{Introduction}

Genetic variability is the pre-requisite for any successful crop improvement programme. It has been argued that, one of the reasons for failure to achieve breakthrough in productivity in self pollinated crops in lack of sufficient variability. The presence of linkage blocks and inverse relations among the correlated characters are most common in these crops which hinder the improvement. Under such circumstances, conventional breeding methods, such as pedigree, bulk and back cross methods are used for handling the segregating generations in self pollinated crops which again impose restrictions on the chance of better recombination are also associated with the weakness of causing rapid homozygosity and low genetic variability.

These conventional methods do not provide any opportunity for reshuffling of genes. Biparental mating, on other hand, is expected to break larger linkage blocks and provide 
more chances for recombination than the selfing series. It is a successful system of inter mating for increase variability and may appropriately be applied where lack of desired variation is the immediate bottleneck in the breeding programme.

The concept of biparental mating was originally developed by Comstock and Robinson in 1948 and 1952. In this technique, plants are randomly selected in $\mathrm{F}_{2}$ or a subsequent generation of a cross and selected plants are crossed (inter se mated) in a definite scheme. In other hands, random inter se mating among $\mathrm{F}_{2}$ individuals or advanced generations is referred to as "Biparental mating", and the resulting progenies are termed as biparental progenies (BIPs). The underlying concepts of biparental progenies is that rare recombinants which remain restricted due to linkage disequilibrium are promptly released by forced recombination and become available for selection in early segregating generations $\left(\mathrm{F}_{3} / \mathrm{F}_{4}\right)$. The great utility of BIPs is in getting precise estimates of additive $\left(\delta^{2} \mathrm{~A}\right)$ and dominance $\left(\delta^{2} \mathrm{D}\right)$ component of genetic variance and average level of dominance. Biparental crosses include full-sib and half-sib progenies in the mating, are based on following assumptions. 1. Random distribution of genotypes. 2 . Random choice of plants for mating. 3. Regular diploid segregation. 4. Absence of maternal effect, epistasis and linkage, 5. Lack of multiple alleles and 6. Equal survival of all the genotypes.

The salient features of biparental mating are as (Singh and Narayanan 2009).

1. This technique involves $\mathrm{F}_{2}, \mathrm{P}_{1}$ and $\mathrm{P}_{2}$ generations of a single cross to develop material for testing.

2. It requires three crop seasons for generating experimental material and fourth season for evaluation.

3. This technique provides information about additive and dominance components of genetic variance.

4. It helps in the choice of breeding procedure for genetic improvement of polygenic traits.

5. Analysis is based on second order statistics. Moreover, analysis is more difficult than generation mean analysis.

6. Biparental crosses include full sib and half sib progenies in the mating programme.

The genetic improvement of any crop mainly depends on the presence of substantial magnitude of variability in the population. On the other hand, biparental mating among the segregants in the $F_{2}$ of a cross may provide more opportunity for the recombination to occur, made up desirable genes and as a result release concealed variability (Parameshwarappa et al., 1997). This would enable to isolate genotypes with desirable combination of traits leading to higher seed yield in crops plants. The seed yield in self pollinated crops is a function of number of branches, tillers, seed numbers and seed weight and there is need to strike a balance among these traits, for which increased variability is essential. Similar results earlier reported by Nagaraj et al., (2002), Narendra Singh (2004) in chickpea, Nanda et al., (1990) in bread wheat, Koli et al., (2012 and 2013) in aromatic rice. The conventional breeding methods are impose restriction on the chances of better recombination's and also associated with the weakness of causing rapid homozygosis and low genetic variability. In view of the above facts, an attempt has been made in the present study to compare the performance of biparental progenies with the selfed generation in releasing genetic variability. Three mating designs for biparental crosses, commonly known as North Carolina Design 1, II and III, have been proposed (Comstock and Robinson1952). 
1. North Carolina design -1:- A polygamous mating design, where one male is crossed with more than one females chosen randomly. This design is an extension of top-cross and line $x$ tester design.

Development of BIPs: In this scheme, five plants are randomly selected from $\mathrm{F}_{2}$ or subsequent generations of a cross. One of these plants is designated as male and is crossed with each of the remaining four plants, which are referred to as female plants. The set of four full-sib families thus produced is denoted as a male group; four such male groups (16 female groups) constitute one set. A female group consists of one full-sib family produced by crossing one female plant with one male plant. In this scheme, a female plant is used for only one mating, while each male is mated to four different females. The number of female mated to each male may be more than four and may vary from one male to another, but usually it is kept uniform for ease in statistical treatment. The design separate the variance of progenies in two fractions, viz., (i) variance due to males $\left(\delta^{2} \mathrm{~m}\right)$, which is equal to $1 / 4 \delta^{2} \mathrm{~A}$, and (2) variance due to female $\left(\delta^{2} \mathrm{f}\right)$, which is equal to $1 / 4 \delta^{2} \mathrm{~A}+1 / 4 \delta^{2} \mathrm{D}$. Therefore, $\delta^{2} \mathrm{~A}=4 \delta^{2} \mathrm{~m}$ and $\delta^{2} \mathrm{AD}=4\left(\delta^{2} \mathrm{f}-\delta^{2} \mathrm{~m}\right)$. This design earlier used for create new populations with high frequencies of rare recombinants in late cauliflower ( Brassica oleracea var. botrytis L.) by Kanwar and Korla (2004), Jagdish et al., (1984) and Tarsem et al., (1990).

\section{Statistical analysis}

\section{Interpretation and implications of results}

Variance components: if the significance of MMS and FMS indicated substantial contribution of males and females, respectively to the variation among BIPs. However, MMS > AMS, the role of males is predominant. Both $\delta^{2} \mathrm{~m}$ and $\delta^{2} \mathrm{f}$ are greater than $\delta^{2} \mathrm{e}$ indicates, environmental contribution to variation is very low.

Heritability estimates: High heritability $(>100 \%)$ is, though indicative of sampling error. If heritability $(\geq 100)$. Nevertheless, it is enough to conclude that there exists an ample amount of additive variance; hence selection for particular traits ought to be effective in the $\mathrm{F}_{2}$ generation.

Average degree of dominance: two statistics, average degree of dominance and dominance ratio determine the average level of dominance. Thus,

Average degree of dominance $=0$ means no dominance

Average degree of dominance $=1.0$ means complete dominance

Average degree of dominance $>1.0$ means over dominance

Average degree of dominance $<1.0$ means partial or incomplete dominance

2. North Carolina Design -I1: A Polyandrous mating design, where one female is crossed more than one male chosen randomly. It is a modified form of NCD-1 and it gives the same genetic information as NCD I.

Development of BIPs: In this mating design, equal numbers of males and females plants are randomly selected from the $\mathrm{F}_{2}$ populations and each males is crossed with each female. Thus the total number of crosses produced will be $m \times f$,

Where $m$ is number of males, $f$ is the number of females, and $m=f$.

In this design both maternal and paternal half -sibs are produced. This design separates the variance of progenies in three fractions, viz., 
(i) variance due to males $\left(\delta^{2} \mathrm{~m}=1 / 4{ }^{2} \mathrm{~A}\right)$, (ii) variance due to female $\left(\delta^{2} \mathrm{f}==1 / 4 \delta^{2} \mathrm{~A}\right)$ and, (iii) variance due to males x females $\left(\delta^{2} m \times f=1 / 4\right.$ $\left.\delta^{2} \mathrm{D}\right)$. Significant differences among the biparental progenies for all the traits as whole, reported by Manickavelu et al., (2006) in rice, Rudra et al., (2009) in safflower, Yunus and Paroda (1983) in wheat, Somashekhar et al., (2010) in bhendi and Koli et al., (2013) in aromatic rice.

\section{Statistical analysis}

\section{Interpretation and implications of results}

Variance components: There are same interpretation as for NCD-1. The significance of FMMS indicates that male $\mathrm{x}$ female interactions are highly specific.

Heritability estimates: heritability is 0.50 or $50 \%$ which is more reliable in NCD II than in NCD I.

Average degree of dominance: similar to that of NCD 1. The dominance ratio $\left(\delta^{2} \mathrm{D} /\right.$ $\left.\delta^{2} \mathrm{~A}\right)$ indicating prevalence or otherwise of dominance alleles in the population is $<1.0$, this indicated that, dominant alleles are slightly less frequent than recessive alleles. The estimates of dominance ratio is also more authentic in NCD II than in NCD I.

3. North Carolina Design -I1I: A $F_{2}$ backcrossing design, where randomly selected plants in $\mathrm{F}_{2}$ are used as males to backcross with each of the two parents involved in the cross.
Development of BIPs: In this design, several plants are randomly selected from $\mathrm{F}_{2}$ population and are designated as males. Each male plant is backcrossed to both the parents involved in the cross to produced pairs of backcross progenies. This design separate the variance into two fractions, viz., (i) variance among males $\left(\delta^{2} \mathrm{~m}=1 / 4 \delta^{2} \mathrm{~A}\right)$, and (2) variance due to males $\mathrm{x}$ female $\left(\delta^{2} \mathrm{mxf}=1 / 2 \delta^{2} \mathrm{D}\right)$. This design earlier applied for create new populations with high frequencies in safflower by Rudra et al., (2009), Nemarullah and Jha (1993) in wheat, Somashekhar et al., (2010) in bhendi (Abelmoschus esculentus L.) and Koli et al., (2013) in aromatic rice.

Among the three mating design of biparental crosses, North Carolina design III is more useful and it does not depend on any assumption about the gene frequencies.

\section{Statistical analysis}

\section{Interpretation and implications of results:}

All these interpretation and results are also similar to that in NCD 1 and NCD II. However, as stated earlier since the effects of linkage, if any, are dissipated by backcrossing in NCD III, therefore the estimates of average degree of dominance and $\delta^{2} \mathrm{~A}$ (hence $\mathrm{h}^{2}{ }_{\mathrm{ns}}$ ) are estimated more precisely in the most powerful design, NCD III than in NCD I or NCD II. Thus the order of precision achieved by NCDs is: NCD III > NCD II > NCD I.

Table. 1 Analysis of variance table- $($ whereas, sets $=2$, males $=4$, females $=4$ and reps $=2$ )

\begin{tabular}{|l|l|l|l|l|}
\hline Sources of variation & D.F. & SS & MSS & Expectations \\
\hline Sets $(\mathbf{s})$ & $\mathrm{S}-1=1$ & SSS & SMS & \\
\hline Reps in sets $(\mathbf{r} / \mathbf{s})$ & $\mathrm{S}(\mathrm{r}-1)=2$ & RSS & RMS & \\
\hline Males in sets $(\mathbf{m} / \mathbf{s})$ & $\mathrm{S}(\mathrm{m}-1)=6$ & MSS & MMS & $\delta^{2}$ e $+\mathrm{r} \delta^{2} \mathrm{f}+\mathrm{rn} \delta^{2} \mathrm{~m}$ \\
\hline Females in males in sets $(\mathbf{f} / \mathbf{m} / \mathbf{s})$ & $\mathrm{Sm}(\mathrm{f}-1)=24$ & FSS & FMS & $\delta^{2}$ e $+\mathrm{r} \delta^{2} \mathrm{f}$ \\
\hline Remainder among plots) & S $(\mathrm{mf}-1)(\mathrm{r}-1)=30$ & ESS & EMS & $\delta_{\mathrm{e}}^{2}$ \\
\hline Total & Smfr-1=63 & TSS & & \\
\hline
\end{tabular}


Table. 2 Analysis of variance table- $($ whereas, sets $=2$, males $=4$, females $=4$ and reps $=2$ )

\begin{tabular}{|l|l|l|l|l|}
\hline Sources of variation & D.F. & SS & MSS & Expectations \\
\hline Sets & $\mathrm{S}-1=1$ & SSS & SMS & \\
\hline Reps in sets (r) & $\mathrm{S}(\mathrm{r}-1)=2$ & RSS & RMS & \\
\hline Males in sets (m) & $\mathrm{S}(\mathrm{m}-1)=6$ & MSS & MMS & $\delta_{\mathrm{e}}^{2}+\mathrm{r} \delta^{2} \mathrm{mf}+\mathrm{rf} \delta^{2} \mathrm{~m}$ \\
\hline Females in sets (f) & $\mathrm{S}(\mathrm{f}-1)=6$ & FSS & FMS & $\delta^{2}{ }_{\mathrm{e}}+\mathrm{r} \delta^{2} \mathrm{mf}+\mathrm{rm} \delta^{2} \mathrm{f}$ \\
\hline Male x female in sets (m x f) & $\mathrm{S}(\mathrm{m}-1)(\mathrm{f}-1)=18$ & FMSS & FMMS & $\delta^{2}{ }_{\mathrm{e}}+\mathrm{r} \delta^{2} \mathrm{mf}$ \\
\hline Remainder among plots & $\mathrm{S}(\mathrm{mf}-1)(\mathrm{r}-1)=30$ & ESS & EMS & $\delta^{2}{ }_{\mathrm{e}}$ \\
\hline Total & $\mathrm{Smfr}-1=63$ & TSS & & \\
\hline
\end{tabular}

Table. 3 Analysis of variance table- $($ whereas, sets $=3$, males $=4$, females $=2$ and reps $=2$ )

\begin{tabular}{|l|l|l|l|l|}
\hline Sources of variation & D.F. & SS & MSS & Expectations \\
\hline Sets & $\mathrm{S}-1=2$ & SSS & SMS & \\
\hline Reps in sets (R) & $\mathrm{S}(\mathrm{R}-1)=3$ & RSS & RMS & \\
\hline Inbred lines(Females) in sets $(\mathbf{F})$ & $\mathrm{S}=3$ & FSS & FMS & \\
\hline F2 parents (males) in sets $(\mathbf{M})$ & $\mathrm{S}(\mathrm{m}-1)=9$ & MSS & MMS & $\delta^{2}{ }^{2}+2 \mathrm{r}^{2} \mathrm{~m}$ \\
\hline Female $\mathbf{x}$ Male in sets $(\mathbf{F} \mathbf{x}$ M) & $\mathrm{S}(\mathrm{f}-1)=9$ & FMSS & FMMS & $\delta^{2}+\mathrm{r}^{2} \mathrm{fm}$ \\
\hline Remainder among plots & $\mathrm{S}(2 \mathrm{~m}-1)(\mathrm{r}-1)=21$ & ESS & EMS & $\delta^{2}{ }_{\mathrm{e}}$ \\
\hline Total & $2 \mathrm{Smr}-1=47$ & TSS & & \\
\hline
\end{tabular}

General remarks on Biparental mating design:

(a) Biparental mating serves two purposes: (i)- it tends to enlarge genetic variance within a population, that can be measured, and (ii) it provides most precise estimates of additive and dominance components of genetic variance besides those of heritability and mean degree of dominance.

(b) Presence of non-allelic interactions may bias upwardly the estimate of dominance variance, but additive variance is estimated accurately by NCDs. However, additive variance $\left(\delta^{2} \mathrm{~A}\right)$ is enflated due to coupling phase of linkage. While average degree of dominance is under estimated due to repulsion phase of linkage, NCD III measures and hence offsets the effects of linkages.

(c) Biparental mating design can be applied equally and efficiently to genetically heterogeneous populations including open-pollinated population complexes or intermitting $\mathrm{F}_{2}$ generations.

(d) Biparental mating design can break down the repulsion phase of linkage; hence rare recombinants that remain restricted due to linkage disequilibrium are released, hence become available for selection. Thus, such a mating can alter not only the magnitude but also the nature of the correlations. This aspect has been described in length by Yunus and Paroda (1982) and Srivastava and Sharma (1987).

(e) Biparental mating can be developed in a specific population for the below mentioned twins objectives;

(i) To estimate precisely the variance components characterizing the populations concerned, so that a sound breeding strategy can be formulated for within population improvement. 
(ii) To directly break undesirable linkage even in self-pollinated crops so as to exploit the segregants straightway in breeding.

Thus, biparental mating is an efficient mating design at breeders door step.

\section{References}

Comstock R.E and Robinson H.F. 1948. The components of genetic variance in population of biparental progenies and their use in estimating average degree of dominance. Biometrics, 4: 254-266.

Comstock R.E and Robinson H.F. 1952. Estimation of average dominance of genes. In Heterosis, Gowen, J.W. (Ed.), Lowa State College press. Ames, Pp. 494-515.

Jagdish C., Chatterjee S. S. and Swarup V. 1984. Studies on biparental progenies in cauliflower III: genetic analysis of biparental progenies. Veg. Sci., 11: 132139.

Kanwar M.S. and Korla B.N. 2002. Evaluation of biparental progenies for horticulture and quality traits in late cauliflower (Brassica oleracea var. botrytis L.). Indian J. Genet., 62(4):328330.

Koli N.R. Chandra Praksh and Punia S.S. (2012). Biparental mating in early segregating generation of aromatic rice (Oryza sativa L.). Indian Journal of Agricultural Sciences. 82 (1): 63-65.

Koli N.R., Kumhar B.L., Mahawar R.K. and Punia S.S. (2013). Impact of Biparental mating in aromatic rice ( $O$. sativa $\mathrm{L}$.). Intl.J. Agric. Envi. Biotec. 6 (1): 11-16.

Manickavelu, A., Natarajan, N., Ganesh, S.K. and Gnanamalar, R.P. 2006. Genetic analysis of biparental progenies in rice ( Oryza sativa L.). Asian J. Plant Sciences, 5 (1): 33-36

Namatullah and Jha P.B.1993. Effect of biparental mating in wheat. Crop
Improv. 20:173-178.

Nagaraj Kampli., Salimath P.M. and Kajjidoni S.T. 2002. Genetic variability created through biparental mating in chickpea (Cicer arietinum L.). Indian J. Genet., 62(2):128-130.

Nanda G.S., Singh G and Gill K.S. 1990. Efficiency of inter mating on $\mathrm{F}_{2}$ generation of an intervarietal cross in Bread wheat. Indian J. Genet., 50: 364368.

Narendra Singh 2004. Generation of genetic variability in chickpea (Cicer arietinum L.) using biparental mating. Indian $J$. Genet., 64(4):327-328.

Parameshwarappa, K.G., Kulkarni, M.S., Gulganji, G.G., Kubsad, V.S and Mallapu C.P.1997. An assessment of genetic variability created through biparental mating in safflower. In paper presented in safflower Conff. BARI (Itali), 2-7, June. 228-30.

Rudra Naik V., Bentur M.G. and Parameshwarappa K.G. 2009. Impact of biparental mating on genetic variability and path analysis in safflower. Karnataka J. agric. Sci. 22(1):44-46.

Singh P. and Narayanan S.S. 2009. Biometrical techniques in plant breeding. Kalyani Publication, New Delhi, $4^{\text {th }}$ edition: $133-144$.

Somashekhar, G., Mohan kumal, H.D; Praveen Kumar, B and Sujatha K. 2010. Genetic analysis of biparental mating and selfing in segregating population of Bhendi (Abelmostchus esculentus (L.) Moench. Electronic Journal of Plant Breeding, 1 (6): 1500-1503.

Srivastawa, R.K., and Sharma J.R. 1987. Change in character-associations following biparental mating in a population of opium poppy (Papaver somniferum L.). Crop Improv. 14: 8486.

Tarsem L., Chatterjee S. S. and Swarup V. 1990. Evaluation of biparental 
progenies for the improvement of Indian cauliflower. Veg. Sci., 17: 157166.

Yunus M. and Paroda R.S. 1982. Impact of biparental mating on correlation coefficient in bread wheat. Theor. Appl.
Genet., 62:337-43.

Yunus M. and Paroda R.S. 1983. Extent of genetic variability created through biparental Mating in wheat. Indian J. Genet., 43:6-81.

\section{How to cite this article:}

Koli, N.R., B.K. Patidar, Manoj Kumar and Sandhya. 2018. Biparental Mating; A System of Intermating for Creating Genetic Variability in Segregating Generation for Crop Improvement. Int.J.Curr.Microbiol.App.Sci. 7(08): 3592-3598. doi: https://doi.org/10.20546/ijcmas.2018.708.363 